\title{
Atypical presentation of Crimean-Congo haemorrhagic fever: Lessons learned
}

\author{
H J Krüger, ${ }^{1} \mathrm{MB}$ ChB, Dip PEC (SA); R de Wet, ${ }^{1} \mathrm{MB}$ ChB, Dip PEC (SA); \\ L H Blumberg, ${ }^{2} \mathrm{MB}$ ChB, MMed (Micro), ID (SA), DTM\&H, DOH, DCH; J Weyer, ${ }^{2} \mathrm{PhD}, \mathrm{MPH}$; \\ F G Lemke, ${ }^{1,3}$ MB ChB, Dip PEC (SA), MMed (Emergency Medicine), FCEM (SA) \\ ${ }^{1}$ Department of Emergency Medicine, Robert Mangaliso Sobukwe Hospital, Kimberley, South Africa \\ ${ }^{2}$ Centre for Emerging Zoonotic and Parasitic Diseases, National Institute for Communicable Diseases, National Health Laboratory Service, \\ Johannesburg, South Africa \\ ${ }^{3}$ Division of Emergency Medicine, Faculty of Health Sciences, University of Cape Town, South Africa
}

Corresponding author: F G Lemke (gustavlemke@gmail.com)

\begin{abstract}
An atypical case of Crimean-Congo haemorrhagic fever is presented. The diagnosis of the case in the presence of several comorbidities was complicated and illustrates the importance of maintaining a high index of suspicion for viral haemorrhagic fever in cases presenting with multisystem disease and an epidemiological history that could present opportunities for exposure to a haemorrhagic fever virus.
\end{abstract}

S Afr Med J 2019;109(2):91-94. DOI:10.7196/SAMJ.2019.v109i2.13477

Crimean-Congo haemorrhagic fever (CCHF) is a tick-borne zoonosis caused by a Nairovirus (family: Bunyaviridae) and is endemic in Africa, the Middle East, Asia and southern Europe. ${ }^{[1,2]}$ Humans become infected either directly through the bite of an infected tick (mostly Hyalomma spp. or 'bontpoot' ticks) or through contact with infected animal products, or blood or tissue of infected humans. ${ }^{[1,2]}$ Consequently, the majority of CCHF cases occur in individuals who live and work in rural farming areas, particularly where livestock farming is practised. ${ }^{[1,2]}$ In addition, cases of CCHF in slaughterhouse workers and hunters have been reported. Nosocomial transmission of CCHF virus has also been reported, albeit infrequently. ${ }^{[3-7]}$ The case fatality ratio of CCHF is $~ 30 \% .{ }^{[2]}$ Treatment of CCHF is based on the stage of presentation and is mainly supportive. ${ }^{[8]}$ Blood and platelet transfusions and in some cases inotropic and ventilatory support are typically indicated. Use of the antiviral ribavirin, particularly during the early stages of CCHF, has been advocated in cases with a high index of suspicion and in patients proven to be suffering from CCHF. However, the efficacy of ribavirin in the treatment of CCHF remains controversial in the absence of adequate clinical trials. ${ }^{\left[{ }^{9-13]}\right.}$ Ribavirin is a synthetic nucleoside analogue, available only in the oral formation in South Africa (SA).

Human cases of CCHF are relatively rare in SA, but have been reported from all nine provinces of the country. ${ }^{[3,14]}$ Since the first recognition of CCHF in SA in 1981, 200 human cases have been laboratory confirmed in the country (data source: Jacqueline Weyer, National Institute for Communicable Diseases, August 2018). Historically, the largest numbers of human CCHF cases have occurred in the semi-arid livestock farming regions of the Northern Cape, Free State and North West provinces. Tick bites have been reported as the source of exposure in more than two-thirds of CCHF cases in SA, with the remaining cases relating to contact with infected tissues and blood (e.g. abattoir workers and hunters). ${ }^{[15]}$ Cases mostly involve farmers, farm workers and veterinary health workers. ${ }^{[15]}$

In a review of CCHF cases reported in SA, fever with bleeding was found to be common. ${ }^{[14-16]}$ This was also reported for CCHF patients from Eastern Europe, Turkey and the Middle East. ${ }^{[17-23]}$ In addition, severe headaches that can be defined as migraines are often reported. ${ }^{[14,16-17]}$ Importantly, however, several studies have reported diagnosis of CCHF in the absence of fever and/or overt bleeding signs. ${ }^{[22,23]}$ Nevertheless, the classic case definition of CCHF (and other viral haemorrhagic fever (VHF)) remains primarily based on patients presenting with acute onset of fever with bleeding signs and a compatible epidemiological history. ${ }^{[24,25]}$ The recognition of unusual cases of VHF such as CCHF is problematic, as it implies delays in the triggering of infection prevention and control procedures to prevent nosocomial exposures and public health responses to identify and manage potential contacts and secondary infections.

We report an atypical case of CCHF in SA and present important lessons learned through the management of the case.

\section{Case report}

A 62-year-old man who farmed sheep, cattle and goats in the northeastern Northern Cape Province presented with flu-like symptoms, including malaise and dyspnoea, in the winter month of June 2017. The patient was known to have type 2 diabetes, benign prostatic hyperplasia and hypertension, and was obese. His chronic treatment regimen included $500 \mathrm{mg}$ metformin, $4 \mathrm{mg}$ perindopril and $0.4 \mathrm{mg}$ tamsulosin daily. Apart from the comorbidities, no recent travel history, insect bites (as confirmed by the patient, but also no bite marks or eschars were noted on examination) or contact with animals known to be sick were reported.

The patient had a 5-day history of progressively worsening headache, malaise and myalgia, and had been treated by a general practitioner (GP) 3 days before presentation to hospital. He had developed tachypnoea, ataxia, polydipsia, anorexia and nausea on the day of this consultation. The GP prescribed broad-spectrum oral antibiotics and doubled the patient's metformin dosage.

Because the patient still felt unwell, he referred himself to the emergency centre. That day, he was restless and vomited. He was apyrexial on admission and was ambulant, and most findings on clinical examination were unremarkable. On the way to the hospital he cut his finger, and excessive bleeding that was difficult to stem was 
noted. On initial examination there was marked ecchymosis after the non-invasive blood pressure cuff was removed. Initially, the patient's bedside glucose level tested at $18.0 \mathrm{mg} / \mathrm{dL}$, with $1+$ ketones and $3+$ blood on the urine dipstick, with oliguria noted. Further bedside testing indicated a metabolic crisis, which was surprising given his unremarkable clinical picture (Table 1). Following these test results, the initial working diagnosis was a high anion gap metabolic acidosis caused by either diabetic ketoacidosis with possible sepsis or an inadvertent metformin overdose. Supportive treatment was initiated with fluid resuscitation, electrolyte abnormality correction, broad-spectrum antibiotics and septic work-up. As per the institutional diabetic ketoacidosis protocol, an insulin infusion was also initiated.

Formal blood results indicated that the patient was severely thrombocytopenic, with a high haemoglobin concentration of $18.0 \mathrm{~g} /$ dL (Table 2). Deranged liver and renal function indicated multisystem involvement.

The diagnosis of VHF was considered at this point, given that the patient was a farmer with unexplained multiorgan failure and coagulopathy, and the institutional CCHF protocol was activated. A risk score developed by Swanepoel et al. ${ }^{[14]}$ assigns a score to relevant symptoms, signs and investigations to determine the probability of CCHF and the need to institute treatment. The patient scored 12, which according to this tool requires consideration of CCHF as a

Table 1. Summary of point-of-care venous blood gas and blood results obtained shortly after admission

\begin{tabular}{lll}
\hline Marker & Result & Reference range \\
\hline $\mathrm{pH}$ & $7.01($ low $)$ & $7.35-7.45$ \\
$\mathrm{pCO}_{2}(\mathrm{kPa})$ & 5.25 & $4.66-6.38$ \\
$\mathrm{HCO}_{3}(\mathrm{mmol} / \mathrm{L})$ & $10.3($ low $)$ & $19-24$ \\
Base excess $(\mathrm{mmol} / \mathrm{L})$ & $-19.8($ low $)$ & $-2.0-3.0$ \\
Urea $(\mathrm{mmol} / \mathrm{L})$ & $15.4($ high $)$ & $2.1-7.1$ \\
Creatinine $(\mu \mathrm{mol} / \mathrm{L})$ & $296($ high $)$ & $64-104$ \\
Lactate $(\mathrm{mmol} / \mathrm{L})$ & $18.2($ high $)$ & $0.5-1$ \\
Potassium $(\mathrm{mmol} / \mathrm{L})$ & $5.7($ high $)$ & $3.5-4.5$ \\
$\mathrm{pCO}_{2}=$ partial pressure of carbon dioxide; $\mathrm{HCO}_{3}=$ bicarbonate.
\end{tabular}

possible diagnosis even in the absence of fever. The patient continued to deteriorate progressively with severe hypotension and tachycardia, a worsening $\mathrm{pH}$ of 6.7 and unreportable high lactate on a repeat venous blood gas profile. Notably, he also started bleeding and oozing from venepuncture sites. Inotropic support and a sodium bicarbonate bolus were initiated, but the patient had a cardiac arrest and died.

Blood samples were collected post mortem and transferred to the National Institute for Communicable Diseases for laboratory investigation for VHF. The clinical diagnosis of CCHF was confirmed by reverse transcription polymerase chain reaction testing.

\section{Discussion}

CCHF is generally considered in the differential diagnosis of a patient with fever and bleeding, particularly if an epidemiological risk factor (such as a tick bite) is identified. ${ }^{[14,16-23]}$ Atypical cases of CCHF have been reported infrequently in published studies. Guven et al. ${ }^{[26]}$ described a case of CCHF in a patient who presented with hepatorenal failure but no fever. The patient was hypotensive, hypothermic, anuric and hypoxic, and had severe metabolic acidosis. With no history of tick bites or other predisposing activities reported, the patient was scheduled for a liver transplant but died 1 day after admission. A diagnosis of CCHF was only considered and investigated when a family member of the patient was diagnosed with CCHF about a week after the patient's death. The family members had had a picnic together a week before the undiagnosed patient became ill, so it is possible that they were in fact exposed to ticks. Another report described a patient presenting with acute abdominal pain, fever, malaise, headache, vomiting, diarrhoea and bleeding. ${ }^{[27]}$ The patient experienced abdominal discomfort on palpation, and acute appendicitis was suspected. A laparotomy was performed before a diagnosis of CCHF was confirmed in this case. Ardalan et al. ${ }^{[28]}$ reported a case involving a young female who was diagnosed with thrombocytic microangiopathy and renal failure. Postmortem investigations confirmed a diagnosis of CCHF. Cases have also been reported where the presence of unrelated symptoms associated with comorbid conditions could thwart the CCHF diagnosis, for example a CCHF case with previously undiagnosed chronic myeloid leukaemia. The patient presented with a clinical picture and exposure history

\section{Table 2. Formal blood results}

\begin{tabular}{|c|c|c|}
\hline Marker & Result & Reference range \\
\hline White cell count $\left(\times 10^{9} / \mathrm{L}\right)$ & 12.73 (high) & $3.92-10.4$ \\
\hline Haemoglobin (g/dL) & 18.0 (high) & $13.4-17.5$ \\
\hline Haematocrit (L/L) & 0.587 (high) & $0.39-0.51$ \\
\hline Platelet count $\left(\times 10^{9} / \mathrm{L}\right)$ & 7 (low) & $171-388$ \\
\hline Urea $(\mathrm{mmol} / \mathrm{L})$ & 16.2 (high) & $2.1-7.1$ \\
\hline Creatinine $(\mu \mathrm{mol} / \mathrm{L})$ & 399 (high) & $64-104$ \\
\hline Calcium $(\mathrm{mmol} / \mathrm{L})$ & 2.78 (high) & $2.15-2.50$ \\
\hline Magnesium (mmol/L) & 1.54 (high) & $0.63-1.05$ \\
\hline Inorganic phosphate $(\mathrm{mmol} / \mathrm{L})$ & 4.60 (high) & $0.78-1.42$ \\
\hline Alanine transaminase $\left.\mathrm{I}^{*} \mathrm{IU} / \mathrm{L}\right)$ & 547 (high) & $10-40$ \\
\hline Alkaline phosphatase (IU/L) & 165 (high) & $53-128$ \\
\hline Gamma-glutamyl transferase (IU/mL) & 657 (high) & $<68$ \\
\hline Lactate dehydrogenase (IU/L) & 3557 (high) & $100-190$ \\
\hline Creatine kinase (IU/L) & 1281 (high) & $<200$ \\
\hline C-reactive protein $(\mathrm{mg} / \mathrm{L})$ & 79 (high) & $<10.0$ \\
\hline International normalised ratio & 3.62 (high) & $0.8-1.2$ \\
\hline D-dimer quantitative (mg/L) & 3.26 (high) & $<0.46$ \\
\hline Activated partial thromboplastin time (s) & 104.1 (high) & $30.0-40.0$ \\
\hline
\end{tabular}


compatible with CCHF, but a highly elevated white blood cell count $\left(75 \times 10^{9} / \mathrm{L}\right)$ and splenomegaly did not fit with that diagnosis. ${ }^{[29]}$

The differential diagnosis of CCHF is extensive and in the SA context could include, but is not limited to, bacterial septicaemia (with or without HIV infection), rickettsiosis, Q fever, listeriosis, infection with hepatitis viruses, brucellosis, malaria, meningococcaemia, and if the patient has a compatible travel history, other haemorrhagic fever viruses. ${ }^{[14-16]}$

It is therefore clear that the clinical recognition of CCHF is complicated by many factors. Given that CCHF has a case fatality ratio of up to $30 \%$, and that the virus has been associated with nosocomial transmission in the past, atypical cases resulting in delayed diagnosis may have dire consequences. For example, in the case reported by Guven et al., ${ }^{[26]}$ more than 50 healthcare workers were exposed to the patient. Intensive public health responses, including case tracing, clinical monitoring and provision of ribavirin as prophylaxis, were needed to manage and prevent any subsequent cases.

In our case, an atypical presentation (based on initial examination and bedside blood results) together with several comorbid factors obscured the early diagnosis. In addition, although the patient was a farmer from an area where CCHF has been reported previously, this event occurred during a winter month when tick activity and consequently also the risk of CCHF would be expected to be low. Importantly, the patient was apyrexial on examination, and fever is a very common finding with CCHF. For example, in a study reviewing the clinical features of 160 CCHF patients, fever was noted in $99.4 \%$ of cases. ${ }^{[30]}$ Since it was reported that the patient had been ill for 5 days prior to admission, a history of antipyretic use is important to consider as a possible reason for apyrexial presentation. Regardless of this uncommon presentation, given the fact that the patient was a farmer from a CCHF endemic area, the blood results indicating multisystem involvement and the clinical presentation (apart from no fever), including bleeding signs (ecchymosis, bleeding from venepuncture sites), could fit the diagnosis of CCHF. This was reiterated by the risk scoring using the Swanepoel criteria, ${ }^{[31]}$ which indicated that this patient should be managed as a possible CCHF case, and the requirement of specific laboratory testing to confirm the diagnosis. The Swanepoel criteria rely on three categories to stratify the risk of CCHF in a patient. The categories consist of exposure history, signs and symptoms, and findings of laboratory investigations. A score of $\geq 12$ points would be an indication to manage a patient as a possible case of CCHF. The likelihood of certain infectious diseases plummets if there has been no relevant context in which exposure may have occurred.

Importantly, the case presented here illustrates that clinicians should be wary of the clinically 'well-looking' patient with an underlying biochemical catastrophe. The epidemiological context of the case should not be overlooked. Given CCHF endemicity in SA, together with the patient being a farmer from an area where CCHF is commonly reported, CCHF was considered as part of the differential diagnosis and appropriate infection prevention and control measures and other public health responses were triggered promptly. In such a case, specific laboratory investigations should be performed as soon as possible to confirm or exclude the diagnosis.

\section{Conclusion}

It is important for healthcare workers in an area where a rare but potentially fatal disease such as CCHF occurs not only to be aware of the disease presentation (with possible atypical or confounding symptomatology), differential diagnosis and management on a professional level, but also to have preparations in place for a systematic response in the first few hours, led by the frontline personnel, until a district or provincial response gains traction.

\section{Teaching points}

- Re-evaluate patients frequently to assess their response to specific treatment interventions. If patients are not responding as expected, reconsider the diagnosis and treatment strategy.

- Institutions in at-risk regions for VHF should have clear institutional protocols and regular staff training to ensure smooth activation of the protocol when needed.

- Always wear protective equipment when dealing with body fluids and secretions. Treat all fluids and secretions as potentially infectious.

- Common things occur commonly, but occasionally the hoofbeats you hear belong to a zebra. Especially in Africa.

\section{Declaration. None.}

Acknowledgements. The authors thank the healthcare workers at Robert Mangaliso Sobukwe Hospital Emergency Centre for their support in case management, the National Health Laboratory Service and National Institute for Communicable Diseases (Centre for Emerging Zoonotic and Parasitic Diseases) for laboratory support, and the provincial communicable disease team for public health responses related to this case. They also thank Drs Ahmad Mazanderani and Carl Reddy of the National Institute for Communicable Diseases for clinical consultation and support.

Author contributions. HJK, RdW and FGL were involved in the management of the case presented. LHB and JW were involved in the laboratory diagnosis. All authors contributed to the drafting of the manuscript.

\section{Funding. None.}

\section{Conflicts of interest. None}

Consent for publication. Written informed consent for publication was provided by the patient's nearest living relative.

1. Bente DA, Forrester NL, Watts DM, McAuley AJ, Whitehouse CA, Bray M. Crimean-Congo hemorrhagic fever: History, epidemiology, pathogenesis, clinical syndrome and genetic diversity. Antiviral Res 2013;100(1):159-189. https://www.ncbi.nlm.nih.gov/pubmed/23906741

Ergönül Ö. Crimean-Congo haemorrhagic fever. Lancet Infect Dis 2006;6(4):203-214. https://doi Ergönül O. Crimean-Congo haemo
org/10.1016/s1473-3099(06)70435-2

3. Richards GA, Weyer J, Blumberg LH. Viral haemorrhagic fevers in South Africa. S Afr Med 2015;105(9):748-751. https://doi.org/10.7196/SAMJnew.8330

4. Pshenichnaya NY, Nenadskaya SA. Probable Crimean-Congo hemorrhagic fever virus transmission occurred after aerosol-generating medical procedures in Russia: Nosocomial cluster. Int J Infect Dis 2015;33:120-122. https://doi.org/10.1016/j.ijid.2014.12.047

5. Conger NG, Paolino KM, Osborn EC, et al. Health care response to CCHF in US soldier and nosocomial transmission to health care providers, Germany, 2009. Emerg Infect Dis 2015;21(1):23-31. https://doi.org/10.3201/eid2101.141413

6. Leblebicioglu H, Sunbul M, Guner R, et al. Healthcare-associated Crimean-Congo haemorrhagic fever in Turkey, 2002 - 2014: A multicentre retrospective cross-sectional study. Clin Microbiol Infect 2016;22(4):387-el. https://doi.org/10.1016/j.cmi.2015.11.024

7. Chinikar S, Shayesteh M, Khakifirouz S, et al. Nosocomial infection of Crimean-Congo haemorrhagic Chinikar S, Shayesteh M, Khakifirouz S, et al. Nosocomial infection of Crimean-Congo haemorrhagic
fever in eastern Iran: Case report. Travel Med Infect Dis 2013;11(4):252-255. https://doi.org/10.1016/j. tmaid.2012.11.009

8. Leblebicioglu H, Bodur H, Dokuzoguz B, et al. Case management and supportive treatment for patients with Crimean-Congo hemorrhagic fever. Vector Borne Zoonotic Dis 2012;12(9):805-811. https://doi.org/10.1089/vbz.2011.0896

9. Yilmaz G, Sunbul M, Yapar D, et al. Ribavirin in treatment of Crimean-Congo hemorrhagic fever (CCHF): An international multicenter retrospective analysis. https://idsa.confex.com/idsa/2016 webprogram/Paper59378.html (accessed 3 January 2019).

10. Espy N, Pérez-Sautu U, Ramírez de Arellano E, et al. Ribavirin has a demonstrable effect on CrimeanCongo hemorrhagic fever viral populations and viral load during patient treatment. J Infect Dis 2018;217(12):1952-1956. https://doi.org/10.1093/infdis/jiy163

11. Ozbey SB, Kader C, Erbay A, Ergönül Ö. Early use of ribavirin is beneficial in Crimean-Congo hemorrhagic fever. Vector Borne Zoonotic Dis 2014;14(4):300-302. https://doi.org/10.1089/ vbz.2013.1421

12. Ergönül Ö. Evidence supports ribavirin use in Crimean-Congo hemorrhagic fever. Int J Infect Dis 2014;29(12):296. https://doi.org/10.1016/j.ijid.2014.08.016

13. Johnson S, Henschke N, Maayan N, et al. Ribavirin for treating Crimean Congo haemorrhagic fohson S, Henschke N, Maayan N, et al. Ribavirin for treating Crimean Congo haemorrhagic
fever (Review). Cochrane Database Syst Rev 2018, Issue 6. Art. No.: CD012713. https://doi. fever (Review). Cochrane Database Syst
org/10.1002/14651858.CD012713.pub2

14. Swanepoel R, Gill DE, Shephard AJ, Leman PA, Mynhardt JH. The clinical pathology of CrimeanCongo hemorrhagic fever. Rev Infect Dis 1989;11(Suppl 4):S794-S800. https://doi.org/10.1093/ clinids/11.supplement_4.s464

15. Kemp A, Msimang V, Weyer J, Paweska JT. Crimean-Congo haemorrhagic fever and tick bite fever in South Africa, 2012 - 2014. Commun Dis Surveill Bull 2014;12(3):59-62. https://pdfs.semanticscholar org/da4d/9eb76361delclbcd4f6b08413b5d77004ecd.pdf (accessed 3 January 2019). 
16. Richards GA, Weyer J, Blumberg LH. Viral haemorrhagic fevers in South Africa. S Afr Med J 2015;105(9):748-751. https://doi.org/10.7196/SAMJnew.8330

17. Ayatollahi J, Shahcheraghi SH, Mirjalili M. Report of nine cases of Crimean-Congo haemorrhagic fever from Iran. Niger Med J 2015;56(2):156-159. https://doi.org/10.4103/0300-1652.153409

18. Nurmakhanov T, Sansyzbaev Y, Atshabar B, et al. Crimean-Congo haemorrhagic fever virus in Kazakhstan (1948 - 2013). Int J Infect Dis 2015;38(9):19-23. https://doi.org/10.1016/j.ijid.2015.07.007 19. Mourya, DT, Viswanathan R, Jadhav SK, Yadav PD, Basu A, Chadha MS. Retrospective analysis of clinical information in Crimean-Congo haemorrhagic fever patients: 2014 - 2015, India. Indian J Med Res 2017;145(5):673-678. https://doi.org/10.4103/ijmr.IJMR_65_16

20. Kilinc C, Gückan R, Capraz M, et al. Examination of the specific clinical symptoms and laboratory findings of Crimean-Congo hemorrhagic fever. J Vector Borne Dis 2016;53(2):162-167.

21. Aksoy D, Barut H, Duygu F, Cevik B, Kurt S, Sümbül O. Characteristics of headache and its relationship

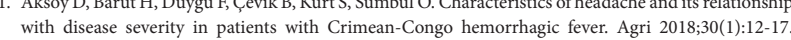
with disease severity in patients with
https://doi.org/10.5505/agri.2017.76259

22. Krasniqi M, Bino S. Clinical and laboratory findings of Crimean-Congo hemorrhagic fever in Albania in 2013 - 2015. Int J Health Sci 2016;4(1):31-34. https://doi.org/10.15640/ijhs.v4nla4

23. Yilmaz GR, Buzgan T, Irmak H, et al. The epidemiology of Crimean-Congo hemorrhagic fever in Turkey, 2002 - 2007. Int J Infect Dis 2009;13(3):380-386. https://doi.org/10.1016/j.ijid.2008.07.021

24. National Department of Health, South Africa. National guidelines for the recognition and management of viral haemorrhagic fevers 2014. http://www.nicd.ac.za/assets/files/National\%20Guidelines\%20 for $\% 20$ Recognition $\% 20$ and $\% 20$ Management $\% 20$ of $\% 20$ Viral $\% 20$ Haemorrhagic $\% 20 \% 20 \% 20$.pdf (accessed 10 July 2018)

25. World Health Organization. Clinical management of patients with viral haemorrhagic fever. February 2016. http://apps.who.int/iris/bitstream/handle/10665/205570/9789241549608_eng.pdf;jsessionid=B 8FF8E68EC7F759E51ACF4BBDFF9A4A2? sequence=1 (accessed 10 July 2018).
26. Guven G, Talan L, Altintas ND, Memikoglu KO, Yoruk F, Azap A. An unexpected fatal CCHF case and management of exposed health care workers. Int J Infect Dis 2017;55:118-121. https://doi. org/10.1016/j.ijid.2016.12.026

27. Çelikbaş A, Ergönül Ö, Dokuzoğuz B, Eren S, Baykam N, Polat-Düzgün A. Crimean Congo hemorrhagic fever infection simulating acute appendicitis. J Infect 2005;50(4):363-365. https://doi. org/10.1016/j.jinf.2004.05.020

28. Ardalan MR, Tubbs RS, Chinikar S, Shoja MM. Crimean-Congo haemorrhagic fever presenting as thrombotic microangiopathy and acute renal failure. Nephrol Dial Transplant 2006;21(8):2304-2307. https://doi.org/10.1093/ndt/gfl248

29. Coetzee MJ, Blumberg LH, Paweska JT, Leman P, Swanepoel R, de Kock A. Crimean-Congo haemorrhagic fever presenting with undiagnosed chronic myeloid leukaemia. South Afr J Infect Dis 2017;32(4):142-144. https:///doi.org/10.1080/23120053.2017.1345493

30. Osquee HO, Pourjafar H, Taghizadeh S, Haghdoost M, Ansari F. Laboratory features of 160 CCHF confirmed cases in Zabol of Iran: A 10-year study. J Infect 2017;74(4):418-420. https://doi. org/10.1016/j.jinf.2016.12.003

31. Swanepoel R, Shepherd AJ, Leman PA, et al. Epidemiologic and clinical features of CrimeanCongo hemorrhagic fever in southern Africa. Am J Trop Med Hyg 1987;36(1):120-132. https://doi. org/10.4269/ajtmh.1987.36.120

Accepted 17 October 2018 